\title{
Research on Power Grid Investment Risk of Set-Analysis Method in New Electricity Reform
}

\author{
Jianchang Lu and Dandan Xing \\ Department of Economic Management, North China Electric Power University, Baoding 071003, Hebei Province, China
}

\begin{abstract}
In view of the change in the profit model of the power grid under the new power reform, If grid companies want to improve their economic efficiency, they must expand the scale of effective assets of fixed assets and increase the number of effective assets within the understanding of the demand for electricity.By determining the factors affecting the power grid investment in the new environment,a risk model for the power grid investment under the new power reform is constructed.First,this paper uses the set pair analysis method algorithm and derives the relevant formula to quantify uncertainties in grid investment risk. Then,it gets the results of the calculation of the degree of connection of each scheme and combine set pair events with a net present value less than 0 for each set evens.At last,based on the above results, we get the best investment plan.Verified by the case of the HBN grid company,it shows that the investment risk model established is feasible and can provide an appropriate reference for the new power companies to change their investment decisions.
\end{abstract}

\section{Introduction}

After the Spontaneous Reform Commission issued the electricity reform No. 9, it promulgated the "Provincial Transmission and Distribution Pricing Method" in 2016.The introduction of the "Method" has changed the profit model of grid companies, which used to rely on the purchase and sale of electricity to earn the difference. In the new profit mode, the source of benefits for grid companies is mainly from the network fee for transmission and distribution. According to the method, the electricity price of transmission and distribution consists of three parts, which are the allowable cost, the allowable income and the price inside tax respectively. The permitted costs and permitted benefits are all related to the scale of effective assets. Therefore, by increasing the effective assets of grid enterprises, the power transmission and distribution price can be raised, so as to improve the operating income when the electricity transmission and distribution quantity is certain.

Literature [1] describes the importance of the assets management of grid enterprises in the new situation and establishes a regression model under the new transmission and distribution revenue model. The purpose of this paper is to find the relationship between the assets of power grid enterprises and their benefits and to analyze the sensitivity of related asset class indexes. Finally, the conclusion is drawn that the larger the effective asset size of the grid, the higher the profit level. The main purpose of literature [2] is to improve the operation and management mode of power supply enterprises. In this literature, firstly, the system dynamics method is used to synthesize the articulation of financial indexes, then the decision-making optimization model is constructed, and finally the operation of power grid enterprises is simulated under the new situation. Literature [3] pointed out that power grid enterprises should do a good job in the management of fixed assets and propose the consistent management of account and card items under the new power reform, so as to improve the revenue level of the power grid. The risk of power planning is also a topic that many scholars are keen to study. Literature [4] uses the relationship between the impact factors of grid investment planning and adopts system dynamics related theoretical methods to construct a dynamic model of grid enterprise investment planning. Finally, the author used the actual case to test the feasibility of the model, but it did not make a clear explanation for the quantification of investment risk. The general academic research content of investment risk of power grid project is based on the characteristics of investment power grid project to build various types of power grid project risk assessment model for risk assessment of power grid project [6-8].However, in these studies, because the establishment of the model is relatively simple and the establishment of indicators lacks certain reliability, the evaluation results are often lack of science.

In view of the uncertainty of the grid investment risk assessment under the traditional model, there are electricity sales, purchase price, and electricity price [9]. After the introduction of the "Method", the factors affecting the investment of the grid company project have changed. And according to the new regulations, the 
impact factor needs to be re-determined. In some research materials, there are many ways to evaluate the investment risk of power grids. For example, establishing a cost-benefit model, using net present value, and selecting probability theory static analysis and so on[10]. However, the measurement of the net present value is based on the conditions of the future environment. Under the new power reform, the grid investment faces many complicated changes. The net present value method cannot accurately estimate the investment risk of the project. The literature [11] uses the set pair analysis method to establish the grid investment risk control model in the market environment, and then quantify the risk of grid investment. Although the author uses the dynamic analysis method to study the uncertainty of investment risk, which applied in a novel way, but the applicable environment is inconsistent with the current power industry reform.

Under the new electricity reform provincial power transmission and distribution price regulations, this paper re-determines the uncertainty factors of grid investment cost-benefit parameters and investment risk, and then basing on set pair analysis method builds a revenue model of grid enterprise investment project. And then some parameters are brought into the model to quantify the risk, Then, through formula derivation and calculation of the connection coefficient, the risk quantification results of various investment schemes are obtained, so that the top management can make the optimal investment strategy.

\section{Mathematical model}

\subsection{Set Pair Analysis Method Overview}

$$
\mu(W)=\frac{S}{N}+\frac{F}{N} i+\frac{P}{N} j
$$

$w$ :problem background; $N$ :sum of features; $S$ :common characteristics; $P$ :opposite characteristics. $F$ :difference characteristics. $\mu$ :number of contacts; $i$ :difference coefficient; $j$ :velocity coefficient.Usually assumed $S / N=a ; F / N=b ; P / N=c$; Therefore the above formula can be expressed as:

$$
\mu(w)=a+b i+c j
$$

\subsection{Risk model based on set pair analysis}

In the case of electricity price determination, electricity and annual discount rate are uncertain factors in the investment risk of power grid projects. According to the uncertainty factor in the investment risk of the grid project, the connection degree expression is as follows:

$$
\begin{gathered}
u\left(Q_{1, t}\right)=a_{1, t}+b_{1, t} i+c_{1, t} j=S_{1} / N+F_{1} i / N+P_{1} j / N \\
u\left(Q_{2, t}\right)=a_{2, t}+b_{2, t} i+c_{2, t} j=S_{2} / N+F_{2} i / N+P_{2} j / N \\
u\left(Q_{3, t}\right)=a_{3, t}+b_{3, t} i+c_{3, t} j=S_{3} / N+F_{3} i / N+P_{3} j / N \\
u\left(Q_{4, t}\right)=a_{4, t}+b_{4, t} i+c_{4, t} j=S_{4} / N+F_{4} i / N+P_{4} j / N
\end{gathered}
$$

$$
\begin{aligned}
& u\left(Q_{5, t}\right)=a_{5, t}+b_{5, t} i+c_{5, t} j=S_{5} / N+F_{5} i / N+P_{5} j / N \\
& u\left(Q_{6, t}\right)=a_{6, t}+b_{6, t} i+c_{6, t} j=S_{6} / N+F_{6} i / N+P_{6} j / N \\
& u\left(Q_{7, t}\right)=a_{7, t}+b_{7, t} i+c_{7, t} j=S_{7} / N+F_{7} i / N+P_{7} j / N \\
& u\left(i_{0}\right)=a_{i_{0}}+b_{i_{0}} i+c_{i_{0}} j=S_{8} / N+F_{8} i / N+P_{8} j / N
\end{aligned}
$$

The meaning of the letters in the formula. $N$ :total number; $S_{1}$ :Total net present value of investment less than zero; $P_{1}$ :Total net present value not less than zero; $F_{1}$ :The number of net present values in a fuzzy state; Other formulas have similar meanings

\subsection{Grid investment measurement model based on set pair analysis}

According to the specific application of the net present value formula of the grid investment and the theory of the set pair analysis method, the set pair analysis model of the grid investment project under the new provincial transmission and distribution price regulation can be established:

$$
\begin{aligned}
& \mu(n p v<0)=\frac{1}{n_{1}} \sum_{t=1}^{n_{1}} \mu\left\{\sum_{k=1}^{7}\left(Q_{k, t}, P_{k, t}\right)-\right. \\
& \left.\left[W_{0}\left(1+i_{0}\right)^{n_{1}}-W_{0}\right] \frac{\left(1+i_{0}\right)^{n_{1}} i_{0}}{\left(1+i_{0}\right)^{n_{1}}-1}-S_{0, t} \times 20 \%\right\}
\end{aligned}
$$

In order to facilitate the calculation of the coefficients after the collection, the formula is further simplified. $W_{0}\left(1+i_{0}\right)^{n_{1}}-W_{0}$ simplified to $V_{0}$, which expressed as the need to pay the total financial costs. The model is changed to:

$$
\begin{aligned}
\mu(n p v<0)= & \frac{1}{n_{1}} \sum_{t=1}^{n_{1}} \mu\left\{\sum_{k=1}^{7}\left(Q_{k, t}, P_{k, t}\right)-\right. \\
& \left.V_{0} \frac{\left(1+i_{0}\right)^{n_{1}} i_{0}}{\left(1+i_{0}\right)^{n_{1}}-1}-S_{0, t} \times 20 \%\right\}
\end{aligned}
$$

The grid investment risk level is inferred by the degree of contact, thereby providing managers with information resources for decision making. In this paper, we study the set-pair events in which the grid company's project investment has a net present value less than zero. When the link degree of project investment is greater than 0 , it indicates that there is investment risk in the project, and the investment risk will increase as the contact degree increases. On the other hand, the degree of contact is less than 0 , indicating that the investment risk will become smaller. According to this trend, the investment risk will gradually become smaller, and such investment plans are also easily accepted ${ }^{[11]}$. The grid enterprise management personnel set the threshold according to their actual situation and the degree of resistance to the risk, so as to measure the anti-risk ability.

\section{Case analysis}

HBN Power Grid Corporation is the earliest pilot company to implement the new power reform program, and has collected relevant data through various means. 
The discount rate set in this paper is $6 \%$ (The value of the discount rate involves the impact of economic factors such as loan interest rate, risk-free rate of return, and inflation rate).HBN Grid Corporation was the first pilot of new power reforms in late 2014 and early 2015, so effective data sources began in 2014. The relevant data is as follows:

Table 1. HBN grid company transmission and distribution price list

\begin{tabular}{cccccc}
\hline \multicolumn{5}{c}{ HBN grid transmission and distribution price list (unit: yuan) } \\
\hline Voltage (unit: $\mathrm{kV})$ & $0-1$ & $10(20)$ & 35 & 110 & 220 \\
\hline $\begin{array}{c}\text { General } \\
\text { commercial users } \\
\begin{array}{c}\text { Large industrial } \\
\text { users }\end{array}\end{array}$ & 0.29 & 0.27 & 0.26 & & \\
\hline
\end{tabular}

Table 2. HBN Grid Company Financing Options

\begin{tabular}{cccc}
\hline \multicolumn{4}{c}{ Investment Plan (Unit: 100 million yuan) } \\
\hline Financing plan & A & B & C \\
Financing Amount & 180 & 164 & 194 \\
\hline
\end{tabular}

Table 3. Income from Transmission and Distribution of HBN Power Grid Company

\begin{tabular}{ccc}
\multicolumn{2}{c}{ HBN Power Grid Company's input (unit: 100 million yuan) } \\
\hline years & 2014 & 2015 \\
\hline General commercial users & 56.304 & 55.178 \\
Large industrial users & 152.934 & 149.875 \\
Total count & 209.238 & 205.053 \\
years & 2016 & 2017 \\
General commercial users & 57.054 & 58.556 \\
Large industrial users & 154.973 & 159.051 \\
Total count & 212.028 & 217.607
\end{tabular}

After complicated calculations, the final results of the three scenarios are as follows:

$$
\begin{gathered}
\text { Option A: } \mu_{A}(n p v<0)=-0.2279 ; \\
\text { Option B: } \mu_{B}(n p v<0)=-0.3764 ; \\
\text { Option C: } \mu_{C}(n p v<0)=-0.35
\end{gathered}
$$

In the set-pair event in which the net present value of the grid company's project investment is less than 0 under the new power reform, the connection degree of the three schemes is less than 0 , indicating that the investment risks of the three schemes in the case are relatively small, and thus the three schemes are explained. It is feasible, and the company's senior management can determine which investment plan based on actual conditions. However, the smaller the contact degree is, the smaller the investment risk is. The least the connection degree of the scheme B is the smallest, which indicates that the net present value of the B scheme is the largest among the three schemes, so the scheme B is the optimal choice of this case.

\section{Conclusion}

This paper constructs a net present value model of grid investment income under the new electricity reform, and uses the set pair analysis method to quantify the uncertainty factor risk. Quantitative results based on data from investment plans, it determines the best investment strategy. This paper proves that the constructed investment risk model is feasible through the verification of the investment project of HBN Power Grid Company. Based on the reasonable method of formulating the transmission and distribution price, the grid company needs accurate and effective assets and its key parameters. However, in reality, some grid companies tend to conceal or change important data for the company's profit, so it needs to be related. The department is doing a good job of supervision.

\section{References}

1. Guo Duanhong. Research on asset management and efficiency of power grid enterprises under the background of electric reform [D]. Zhejiang University, 2017.

2. He Yanying. Research on power enterprise decision-making model based on key financial indicators [D]. North China Electric Power University (Beijing), 2016

3. Yang Wei, Yuan Ling, Liu Qi. Research on consistent management strategy of account books in power grid enterprises under the background of electric reform [J]. Electromechanical information, 2016, (36): 154-155.

4. Long Chengfeng. Analysis of the impact of the new electricity reform program on the financial management of power grid enterprises [N]. China Energy News, 2015-08-24 (003).

5. Chen Xu. Research on the construction of risk management system for power grid engineering projects [D]. South China University of Technology, 2016.

6. Yu Huili. Comprehensive decision-making method for transmission network planning scheme considering risk factors [D]. Northeast Electric Power University, 2014.

7. Xing Jun. Research on risk evaluation of power equipment enterprises investing in smart grid projects [D]. Suzhou University, 2013.

8. Wang Mianbin, Tan Zhongfu, Zhang Liying, Cai Wei. Set pair analysis method for grid investment risk assessment in market environment [J]. Chinese Journal of Electrical Engineering, 2010, 30 (19): 91-99.

9. Zhao Keqin. Set pair analysis and its preliminary application [M]. Zhejiang Science and Technology Press. 2000, 23-100. 
10. Wang Mingwu, Jin Juliang, Zhou Yuliang. Set pair analysis coupling method and application [M]. Science Press. 2013, 1-24.

11. Dong Wang, Alistair G. Borthwick, Handan He, Yuankun Wang, Jieyu Zhu, Yuan Lu, Pengcheng $\mathrm{Xu}$, Xiankui Zeng, Jichun Wu, Lachun Wang,
Xinqing Zou, Jiufu Liu, Ying Zou, Ruimin He. A hybrid wavelet de-noising and Rank-Set Pair Analysis approach for forecastinghydrometeorologicaltimeseries [J]. Environmental Research, 2018, 160. 